\title{
OPTIMIZATION OF MIX-DESIGN OF CHEMICALLY RESISTANT SPRAYED CONCRETE
}

\author{
Radek Hermann ${ }^{a, *}$, Rostislav Drochytka ${ }^{b}$, JiŘí Kolísko ${ }^{c}$, \\ Pavel Reiterman ${ }^{d}$ \\ a Brno University of Technology, AdMaS Centre, Purkynova 139, 612 00 Brno, Czech Republic \\ ${ }^{b}$ Brno University of Technology, Faculty of Civil Engineering, Veveri 95, 60200 Brno, Czech Republic \\ ${ }^{c}$ Czech Technical University in Prague, Klokner Institute, Solinova 7, 16608 Prague 6, Czech Republic \\ ${ }^{d}$ Czech Technical University in Prague, Faculty of Civil Engineering, Thakurova 7, 16629 Prague 6, Czech \\ Republic \\ * corresponding author: xherma23@vutbr.cz
}

\begin{abstract}
This paper addresses optimization of mix-design and granulometric curves of aggregate of chemically resistant cementitious sprayed mix. The target of the paper is to improve properties of currently developed mix-design, which has no chemical resistance, and to utilize the secondary raw materials. The mix was optimized by additions improving chemical resistance and binder substituted by secondary raw materials. The binder was substituted by finely ground waste glass and high-temperature fly ash. Filler was substituted with slag from deposit yard and waste sand with soluble glass from steel manufacture. Main observed properties for design of optimized mix were workability time, consistence and physical-mechanical properties. Optimized mix-design successfully replaced all fine parts of filler and up to $30 \%$ of binder while the physical-mechanical properties were preserved or even enhanced. Optimized mix-designs show the same consistencies and workability times.
\end{abstract}

KEYWORDS: Sprayed mix, optimization, secondary raw materials, water absorbing capacity, granulometric curve.

\section{INTRODUCTION}

The problem of sprayed mixes has been solved since the beginning of the $20^{\text {th }}$ century, equipment for application of sprayed concrete was patented in 1911 under the name Cement Gun together with sprayed material, Gunite. Sprayed mixes are usually connected mainly with tunnel works, but use is not limited only to those applications. Use of sprayed concrete has advantages mainly because of its high density, low porosity and overall high quality of sprayed material as such. This material is suitable mainly for applications, where visual properties of final surface are not required. Design of sprayed mixes requires mainly optimization of granulometric curves of aggregate to ensure high density and at the same time very good pumpability of the mix. The important factor is sufficient amount of fines supported by higher proportion of binder and admixtures. Sprayed mixes have their own test procedures, which are described in a set of standards ČSN EN 14488 [1]. Current time focuses on reduction of ecological impacts caused by manufacture of building materials, for this reason, waste or secondary raw materials are used.

Slag. This solid, inorganic and partly melted residuum is produced during combustion of coal or combustible shales on fire grates and in furnaces. This material has high contents of mineral residua of original combustible substance. It is suitable for concrete and mixes; however, properties of slag are not homo- geneous, which may considerably change its quality. Slag very often contains unburned residua of coal, humins, free oxides of calcium and magnesium and other substances, which influences considerably its final behavior in synergy with cement composite. Time of deposit is a very important factor; generally - the longer time of deposit, the higher quality of the slag as such. During deposit time, rain flushes out salts, which may have adverse effect on final mix and create for example efflorescence. Another negative aspect of slag is the fact, many deposit yards are covered with naturally seeded plants, which grow through the deposited slag and final product contains high amount of organic combustible products and hence certain volume instability. In accordance with legislative requirements, slag shall contain the maximum of $10 \%$ of combustibles and for use in concrete, high content of amorphous $\mathrm{SiO}_{2}$ is assumed [2].

Sand with soluble glass. This material is a waste product from steel manufacture. It is a residual material from forms after form removing of cast iron products. This material consists mainly of very pure siliceous sand with content of $80-85 \% \mathrm{SiO}_{2}$, and lower amount of soluble glass. Annual production of waste sand with soluble glass in the Czech Republic is over 30000 tons. There is a generally prevailing opinion, that sand with soluble glass is not suitable for concrete and mortars because of the soluble glass, as this increases amount of alkalis in matrix and may 
contribute to alkali-silica reaction (ASR). However, in lower amounts it has no impact on matrix and is almost required for sprayed concrete because soluble glass as addition accelerates setting and hardening of concrete. Specific weight is similar as that of pure silica in the interval of $2500-2650 \mathrm{~kg} \cdot \mathrm{m}^{-3}$. Sand with soluble glass is suitable because of its granulometry, when used as screened by screens $0.5 \mathrm{~mm}$. However, because of soluble glass, it forms agglomerates of size up to $16 \mathrm{~mm}$ without any external influence [3, 4].

Glass. Glass is a transparent solid material with high content of amorphous $\mathrm{SiO}_{2}$, produced by manufacture from glass batch. The most common glass products are packing material and sheet glass, which is nowadays manufactured with flow method, when the glass is poured on a layer of melted tin and an endless sheet of glass is produced. Recycled glass used as a secondary raw material for manufacture of concrete comes mainly from packing glass. However, glass from automotive industry is used too, in particular windscreens of automobiles, where it is necessary to separate flexible membranes between layers of glass forming the windscreen composite. Waste glass produced during manufacture and glass from sorted waste containers is used for manufacture of glass to reduce cost as temperature of melting broken glass is lower than temperature of melting glass batch. Unfortunately, not all waste glass can be reused for glass manufacture and glass waste is a serious ecological problem. Most frequent glass is soda-lime glass with $50 \%$ of silica sand, $10 \% \mathrm{Na}_{2} \mathrm{CO}_{3}$ (soda), $12 \% \mathrm{CaCO}_{3}$ (lime stone), $18 \%$ crushed splinters of waste glass and $4 \%$ of other substances. This glass represents up to $80 \%$ of overall glass waste. Because of its composition and content of $\mathrm{SiO}_{2}$ it shows high pozzolanic activity, which, together with cement, supports formation of CSH gels in cement matrix. Studies of Keren Zheng [5] state that if size of glass grain is lower than $75 \mu \mathrm{m}$, the material shows sufficient pozzolanic activity. Use of ground glass and generally glass in concrete presents problem of alkali silica reaction (ASR), which is a reaction, when reaction of alkalis (cement) and amorphous silica material (glass) creates in cement matrix new forms of larger volume and these can gradually lead to static failure of the whole structure. Gerry Lee proved in his paper, if the glass is ground to higher specific surface and medium size of particles is lower than $300 \mu \mathrm{m}$, ASR does not occur [5]7].

High temperature fly ash. High temperature fly ash is incombustible residuum formed in thermal power plants during combustion of pulverized coal at temperatures between 1200 and $1700^{\circ} \mathrm{C}$. To separate fly ash from waste gases, power plants use mostly highly effective electro-static separators; fly ash can be easily used for other purposes. As a reaction to growing demand for fly ash in building industry, standard CSN EN 450 8] was elaborated, which prescribes properties and criteria of suitability of fly ash for concrete and mortars. Suitability of fly ash for concrete and mortars requires minimal content of $45 \%$ amorphous $\mathrm{SiO}_{2}$ and maximal content of free $\mathrm{CaO}, \mathrm{MgO}$ and alkalis. High temperature fly ash presents nowadays up to $70 \%$ of all energetic by-products. Thanks to its composition, high temperature fly ash is similar to natural pozzolans. These pozzolanic properties combined with cement help the formation of CSH gels. Specific weight of fly ash is between 2100 and $2600 \mathrm{~kg} \cdot \mathrm{m}^{-3}$. Fly ash influences mainly long-term physical-mechanical properties, which brings considerable enhancement and help enclose the structure cement matrix. This phenomenon also enhances chemical resistance in time [3].

\section{MATERIALS AND METHODS}

For optimization, one of currently developed sprayed fine-grained mixes was selected, which did not show increased chemical resistance before adjustments. Manufacturer supplies partial components; binder was cement CEM I 42.5 R, additions, fillers, polypropylene fibers and admixtures for adjustments of specific properties of the material. Composition of reference is in following Table 1

Mix was adjusted with secondary raw materials. Part of the binder was substituted with finely ground recycled glass from soda-lime glass (Glass) and high temperature fly ash (HFA). Filler was substituted with sand containing soluble glass (SCSG) and slag from former thermal power plant and nearby deposit yard (SSL). Substitution filler, glass with soluble glass and slag were pre-treated with jawed crusher and subsequently with sieve analyzed so that final granulometric curve corresponded with that of original fillers as much as possible. Substitution binders were pretreated with laboratory ball grinder so that specific surface was comparable with specific surface of cement, in particular $400 \mathrm{~m}^{2} \cdot \mathrm{kg}^{-1}\left( \pm 50 \mathrm{~m}^{2} \cdot \mathrm{kg}^{-1}\right)$. Grain size of individual substitution binder is stated in following Tab. 2

All tests and experiments were carried out in accordance with regulations and standards.

Mix-designs. In total, five reference materials were made with all content of binder and filler, the only modified part was content of additions influencing specific properties. Out of these basic mix-designs, one representative was selected based on physicalmechanical properties after 28 days, in particular tensile strength, compressive strength and water absorbing capacity. This mix-design was then modified with secondary raw materials. The influence of these secondary raw materials on the physical-mechanical properties of the high strength cementitious composites was studied in cooperation of Brno university of technology and Klokner institute Czech technical university in Prague. As regards filler, $100 \%$ substitution of given size fraction was tested; as for binder, three levels of substitution were tested for each secondary raw material. After evaluation of physical-mechanical properties after 28 days, above mentioned binders and 


\begin{tabular}{lc}
\hline Component & Proportion in the mix [wt.\%] \\
\hline Portland cement CEM I 42,5 R & $17-25$ \\
Silica sand 0-0.5 mm & $13-18$ \\
Silica sand 0-5.4 mm & $38-45$ \\
Waste from ground feldspar & $4-9$ \\
Ground lime stone & $10-17$ \\
Mix of additions & $1-1.9$ \\
\hline
\end{tabular}

TABle 1. Composition of reference mix.

\begin{tabular}{cccc}
\hline Secondary raw materials & $<0.01 \mathrm{~mm}$ & $0.01-0.063 \mathrm{~mm}$ & $>0.063 \mathrm{~mm}$ \\
\hline High temperature fly ash & 28.84 & 63.35 & 7.87 \\
Recycled glass & 30.71 & 53.12 & 16.18 \\
\hline
\end{tabular}

TABLE 2. Grain size of substitution binders [wt.\%].

fillers were combined in various ways to ensure maximal utilization of secondary raw materials. Materials were mixed separately for each mix from individual raw materials and then mixed with mixing water in the proportion $0.14 \mathrm{~kg}$ of water per $1 \mathrm{~kg}$ of dry mix. Amount of mixing water was slightly adjusted depending on given secondary raw materials to keep the same consistency in fresh state (tested on flow table in accordance with CSN EN 1015-3 [9]). Physicalmechanical properties were tested on test specimens with dimensions $160 \times 40 \times 40 \mathrm{~mm}$, which were placed in water after form removal; tests were carried out after 2, 7 and 28 days of curing.

Laboratory tests. Fresh mixes were subjected to tests to determine density, consistency and time of setting and hardening. Hardened specimens were subjected to tests of physical-mechanical properties - density, tensile strength, compressive strength and after 28 days also water absorbing capacity.

\section{RESUlts AND DISCUSSION}

Physical-mechanical properties. Fig 1 shows compressive strength of reference mix-design and other mix-designs with adjusted composition of additions. These adjusted mix-designs are labeled Bet 0-3 and have completely identical composition and watercement ratio, the only change is amount of additions influencing specific properties of material. Based on the results, one mix-design with the highest compressive strength and lowest water absorbing capacity at the same time will be selected, as the best chemical resistance of such mix-design can be presumed. Selection is assumed after 28 days of maturation and selected mix-design will be subsequently optimized with secondary raw materials.

The results imply that because of using additions affecting specific properties of the material, considerably higher compressive strengths were achieved only after two days while water-cement ratio was the same. To verify properties and determine exact results, suitable mix-design was selected after 28 days of maturation.
Above mentioned mix-designs were subjected to determination of water absorbing capacity. With few exceptions it was confirmed that the higher was the compressive strength value, the lower was water absorbing capacity after 28 days. Mix-design Bet 1 was selected for further optimization, as it showed the best results of physical-mechanical properties. This mix-design was then optimized with secondary raw material to achieve better results than material Bet $R E F$

Following Fig 2 shows compressive strengths of optimized mix-designs based on Bet-1, from which, 5 out of 21 mix-designs were selected for further testing. Compressive strengths of optimized mix-designs are pictured in contrast with reference mix-design Bet $R E F$. In optimized mix-designs, $100 \%$ of fine aggregate is replaced with waste sand with soluble glass from manufacture of steel (SCSG) and subsequently, combinations were tested with waste glass (Glass), high temperature fly ash (HFA) in the amount of 20$30 \%$ of binder substitution (cement) and slag from deposit yard (SSL) as 100\% replacement of coarse aggregate. Test results show that when secondary raw materials are combined with additions, it is possible to achieve strengths which are comparable or even higher than those of reference mix after 28 days combination of waste glass, high temperature fly ash and $30 \%$ substitution of cement. In this mix-design, pozzolanic properties of given materials proved.

The results show that $20 \%$ substitution of cement with waste glass increased compressive strength by $4 \%$, $20 \%$ substitution of cement with high temperature fly ash increased compressive strength by $7 \%$ and $30 \%$ substitution of cement with high temperature fly ash increased compressive strength by approx. $1 \%$ after 28 days. When slag from deposit yard was used, it was necessary to add more than $10 \%$ mixing water to keep the value of workability, which caused considerable reduction of compressive strength and volume weight, results are stated only for information. 


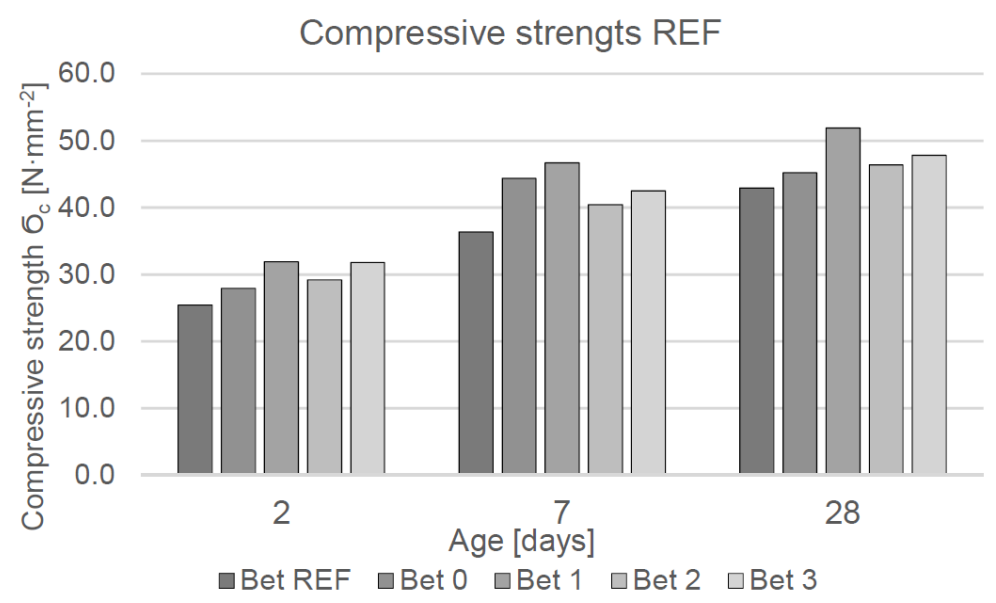

Figure 1. Compressive strengths of reference mix-design.

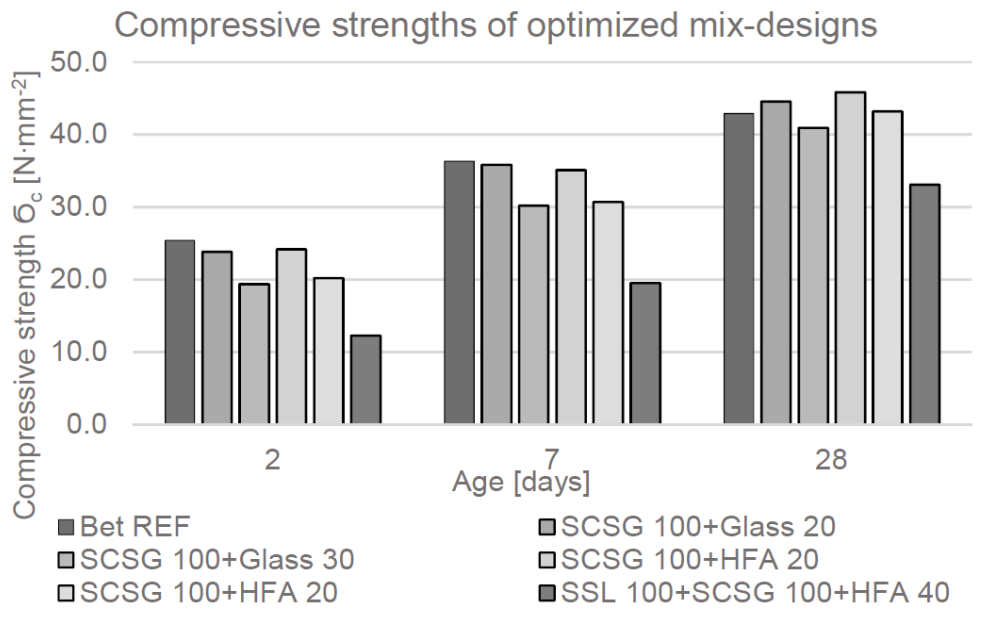

FIGURE 2. Compressive strengths of optimized mix-designs.

\begin{tabular}{lc}
\hline Labeling of mix-design & Water absorbing capacity after 28 days [\%] \\
\hline Bet REF & 10.44 \\
Bet X & 10.29 \\
Bet 0 & 10.12 \\
Bet 1 & 9.37 \\
Bet 2 & 10.39 \\
SCSG $100+$ Glass 20 & 10.83 \\
SCSG 100 + Glass 30 & 10.87 \\
SCSG 100 + HFA 20 & 10.85 \\
SCSG 100 + HFA 30 & 10.92 \\
SSL 100 + SCSG 100 + HFA 40 & 12.65 \\
\hline
\end{tabular}

TABLE 3. Water absorption of individual mix-designs after 28 days. 
Following Tab 3 show values of water absorbing capacity of samples made per individual mix-designs. Water absorbing capacity was determined on fractions of test specimens after the compressive strength test.

Tab3 shows water absorbing capacities of specimens made per individual mix-designs, compared to specimens made per reference mix-design. It is obvious at first sight that water absorbing capacity of optimized mix-designs is higher by $0.4-0.5$ than reference sample. Water absorbing capacity was determined on samples only 28 days old, when it is not expected that properties of used additions and pozzolanic properties of secondary raw materials show their effect. However, because of character of used raw materials it can be assumed, that the value of water absorbing capacity will decrease in time.

\section{Conclusion}

Optimization of additions used in manufacture of above-mentioned sprayed mix could preserve or enhance physical-mechanical properties of reference material. Reference material reached relatively high compressive strengths even after 2 days of curing; these strengths remained sufficient for sprayed application after optimization with secondary raw materials. Use of secondary raw materials verified the hypothesis, that water absorbing capacity of matrix will be increased to certain extent. The usage of the selected secondary raw materials did not cause delay of setting or hardening. It was proved, that when $100 \%$ of finer aggregate was replaced with waste sand with soluble glass, combined with $30 \%$ replacement of binder (cement), the resulting mix shows after 28 days comparable or even better physical-mechanical properties and thanks to selection of secondary raw materials with pozzolanic properties it can be assumed, properties of the material will improve in the course of time. Applicability of the material in more demanding exposition conditions is assumed after at least 60 days, when properties of additions and pozzolanic properties of used materials will manifest. Because of pozzolanic additions, long-term properties are determined too, after 90 days. However, these are not yet available at the time of publishing this paper.

Selected mix-designs will be used for a test spraying and samples made in this way will be subjected to testing of physical-mechanical properties after 2 ,
7, 28 and 90 days including testing water permeability, resistance to chemical de-icing substances and resistance to chemical substances. The target is to create fine-grained sprayed mix with increased resistance to chemical substances and increased life time in demanding exposition conditions.

\section{ACKNOWLEDGEMENTS}

This paper has been worked out under the project No. LO1408 "AdMaS UP - Advanced Materials, Structures and Technologies", and under the project FAST-S-18-5406 "Study of structure of advanced silicate composites focusing on characteristics of action of secondary raw materials".

\section{REFERENCES}

[1] ČSN EN 14488-6: Testing sprayed concrete - Part 6: Thickness of concrete on a substrate. Standard, Czech office for standards, metrology and testing, 2007. In Czech.

[2] Shotcrete design guidelines: design guidelines to avoid, minimise and improve the appearance of shotcrete. Tech. rep., Roads and Traffic Authority of NSW, 2005.

[3] P. Pytlík. Technologie betonu. Vutium, Brno, 2nd edn., 2000.

[4] L. Svoboda, et al. Technologie betonu. Luboš Svoboda, Praha, 3rd edn., 2013.

[5] C. Shi, K. Zheng. A review on the use of waste glasses in the production of cement and concrete. Resources Conservation and Recycling 52:234-247, 2007. DOI:10.1016/j.resconrec.2007.01.013.

[6] V. Bílek. Možnosti využití odpadních písků z výroby vodního skla ve stavebnictví. Master's thesis, Brno University of technology, Faculty of Chemistry, 2013.

[7] H. Lee, A. Hanif, M. Usman, et al. Performance evaluation of concrete incorporating glass powder and glass sludge wastes as supplementary cementing material. Journal of Cleaner Production 170:683-693, 2018. DOI:10.1016/j.jclepro.2017.09.133

[8] ČSN EN 450-1: Fly ash for concrete - Part 1: Definition, specifications and conformity criteria. Standard, Czech office for standards, metrology and testing, 2005. In Czech.

[9] ČSN EN 1015-3: Methods of test for mortar for masonry - Part 3: Determination of consistence of fresh mortar (by flow table). Standard, Czech office for standards, metrology and testing, 2000. In Czech. 